\title{
A pilot survey of post-deployment health care needs in small community-based primary care clinics
}

Polly H Noël ${ }^{1,2^{*}}$, John E Zeber ${ }^{1,2}$, Mary J Pugh ${ }^{1,2}$, Erin P Finley ${ }^{1,2}$ and Michael L Parchman ${ }^{3}$

\begin{abstract}
Background: Relatively little is known regarding to what extent community-based primary care physicians are encountering post-deployment health care needs among veterans of the Afghanistan or Iraq conflicts and their family members.

Methods: This pilot study conducted a cross-sectional survey of 37 primary care physicians working at small urban and suburban clinics belonging to a practice-based research network in the south central region of Texas.

Results: Approximately $80 \%$ of the responding physicians reported caring for patients who have been deployed to the Afghanistan or Iraq war zones, or had a family member deployed. Although these physicians noted a variety of conditions related to physical trauma, mental illnesses and psychosocial disruptions such as marital, family, financial, and legal problems appeared to be even more prevalent among their previously deployed patients and were also noted among family members of deployed veterans.
\end{abstract}

Conclusions: Community-based primary care physicians should be aware of common post-deployment health conditions and the resources that are available to meet these needs.

Keywords: Primary care, Post-deployment health, PTSD, Depression

\section{Background}

Since the initiation of Operations Enduring Freedom and Iraqi Freedom (OEF/OIF), more than 2 million active duty military, military reserve, and national guard members have deployed to Afghanistan or Iraq [1]. Of these, over 40,000 have been killed or wounded in action [2]. Although improvements in battlefield armor, casualty evacuation, and medical care have enhanced survival rates following combat injuries, many survivors of once-lethal injuries now require prolonged medical and rehabilitation care [3-5]. In addition, as many as 1 in 5 veterans who served in Iraq and Afghanistan report symptoms of post-traumatic stress disorder (PTSD), depression, and other mental health problems [6-11]. Forty percent of those who have served in Afghanistan or Iraq have deployed more than once, increasing the

\footnotetext{
* Correspondence: noelp@uthscsa.edu

'VERDICT, Central Texas Veterans Health Care System Scott \& White, 7400

Merton Minter Blvd, San Antonio, Texas 78229 USA

Full list of author information is available at the end of the article
}

risk of developing deployment-related mental health conditions, which rises with the frequency of re-deployments $[1,12,13]$. Furthermore, individuals deployed to Afghanistan and Iraq are on average older than those deployed in previous wars, and therefore also more likely to develop musculoskeletal injuries and chronic illnesses in theatre, such as cardiovascular disease, diabetes, and chronic pain [6,14-18].

The Veterans Healthcare Administration (VHA) was created to provide medical care for veterans who were injured or developed an illness during their military service [19]. Services have expanded to cover economically disadvantaged veterans, while other veterans can receive basic health care services for a co-payment. Although more recent policy changes provide up to 5 years of free health care to OEF/OIF veterans who enroll within 5 years of separation from military service, only about $35 \%$ of those who have separated from military service have sought health care in the VHA $[6,20]$. The combination of significant morbidity and low transition rates 
to the VHA suggests that veterans not seeking care within the VHA may instead be turning to communitybased providers for their medical and/or mental health needs.

In addition, more than 120,000 civilian contractors who have deployed in Afghanistan or Iraq are not eligible for benefits from either the Department of Defense (DoD) or VHA, even though more than 4,000 of them have been injured or killed while deployed [21]. The spouses, children, and other dependents of veterans of the Afghanistan and Iraq wars have also been found to be at increased risk of depression, substance abuse and other mental health problems during and after deployments [22-28]. As these family members are largely ineligible for care within the VA system, they are also likely to seek care in the community. The objective of this pilot study was to explore the experiences of community-based primary care physicians in treating veterans and their family members with post-deployment health care needs.

\section{Methods}

\section{Study Design, Setting, and Participants}

We conducted a cross-sectional survey of primary care physicians working at clinics belonging to the South Texas Ambulatory Research Network (STARNet), a practice-based research network [29]. These unaffiliated small urban and suburban practices, each with 1 or 2 family physicians or general internists, serve a population of primary care patients diverse in demographic characteristics, insurance coverage, and health care needs. We excluded any physicians who provided contract services for the VHA. Sixty physicians active in STARNet during the time of the study met inclusion criteria for participation.

\section{Data Collection}

We created a brief, 9-item survey to assess whether any of the physicians' patients ever reported serving in Afghanistan or Iraq since 2001 in any of the following capacities: active duty military, military reserve, National Guard, civilian contractor, journalist, or other role. Two items asked the physicians to specify the number of patients seen in the last 12 months who reported: 1) being deployed to Afghanistan or Iraq, or 2) having a spouse/partner or close family member who had been deployed. One item assessed 20 categories of problems frequently experienced by individual who have been deployed. These included combat- and non-combat injuries, infectious diseases, sexual trauma, psychiatric disorders, and psychosocial disruptions such as marital, family, and legal or financial problems. Another item assessed 5 categories of psychiatric and psychosocial problems that may have been experienced by family members of those who had been deployed: depression, alcohol or substance abuse, marital difficulties, family problems, and legal or financial problems). Additional items assessed the number of years that physicians had been in practice at the STARNet clinic, the total number of unique patients they treated each year at the clinic, whether they accepted TRICARE insurance (i.e., DoD's health insurance plan for active duty members, National Guard and Reserve members, retirees, and dependents that includes purchased care from civilian providers), and their interest in obtaining continuing education on post-deployment health-related conditions. The survey was distributed by the STARNet coordinator and a research associate to the physicians in person, by mail, fax, and/or e-mail in accordance with their preferences.

The research reported here was conducted in compliance with the Helsinki Declaration. It was reviewed and approved (\#HSC20090379E) by an independent ethics committee, the Institutional Review Board (IRB) of the UT Health Science Center at San Antonio. An IRBapproved information sheet informing participants of their rights as research subjects was attached to the questionnaire.

\section{Analytic Plan}

The surveys were formatted with Teleform ${ }^{\circledR}$ software. Completed surveys were reviewed by trained analysts and scanned into an electronic database. Analyses consisted of univariate statistics to describe the sample and document the proportion of physicians who had seen or treated patients with post-deployment health care needs. The prevalence and diversity of physical and mental health problems noted by the physicians among their patients was also summarized.

\section{Results}

Thirty-seven of 60 physicians returned surveys, yielding a response rate of $61.6 \%$. Respondents indicated that they had been in practice at the STARNet clinics an average (SD) of 12.2 (9) years. Approximately 52\% reported caring for more than 1,000 unique patients yearly while $48 \%$ cared for 1,000 or fewer patients. Thirty (81\%) of the 37 responding physicians reported having 1 or more patients who had informed them that they had been to Afghanistan or Iraq since 2001. Of these, 19 (63\%) had seen patients who had been deployed as active duty military, 10 (33\%) had seen Military Reservists, $9(30 \%)$ had seen members of the National Guard, 15 (50\%) had seen civilian contractors, and $3(10 \%)$ had seen journalists. The majority of the responding physicians $(\mathrm{N}=22,59 \%)$ had seen 10 or fewer patients in the prior 12 months who had informed them that they had been deployed to Afghanistan or 
Iraq, while 5 additional physicians (14\%) reported seeing more than 10 of these patients in the last year alone.

In general, the physicians were more likely to report psychiatric or psychosocial problems, as opposed to physical conditions, among their patients who had been deployed (Table 1). Fourteen physicians reported seeing patients with post-deployment related depression, PTSD, alcohol or substance abuse, or marital or family problems. In contrast, 9 physicians reported caring for patients with one or more of the following deploymentrelated medical conditions: non-combat injury, traumatic brain injury (TBI) or other neurological problem, wound care or re-infection, orthopedic problem related to traumatic injury, hearing loss/tinnitus, or medical illness that developed or worsened during deployment. None of the physicians reported seeing patients with deployment-related amputations or prosthetic devices, sexual trauma, acinetobacter or leishmaniasis, vision loss, or depleted uranium exposure.

Table 1 Post-deployment medical and psychological problems noted among individuals deployed to Afghanistan or Iraq seen by community-based primary care providers $(\mathbf{N}=\mathbf{3 0})$

\begin{tabular}{|c|c|}
\hline Deployment-related Problem & $\mathrm{N}(\%)$ \\
\hline Traumatic amputation and/or prosthetic device & 0 \\
\hline Wound care or re-infection & $\begin{array}{c}3 \\
(10 \%)\end{array}$ \\
\hline Other orthopedic problem related to combat or burn injury & $2(7 \%)$ \\
\hline Traumatic brain injury & $2(7 \%)$ \\
\hline $\begin{array}{l}\text { Other neurological problem related to head injury } \\
\text { (e.g., epilepsy) }\end{array}$ & $1(3 \%)$ \\
\hline $\begin{array}{l}\text { Non-combat injury that occurred during deployment } \\
\text { (e.g., motor vehicle accident) }\end{array}$ & $\begin{array}{c}3 \\
(10 \%) \\
\end{array}$ \\
\hline Vision loss & 0 \\
\hline Hearing loss, tinnitus & $2(7 \%)$ \\
\hline $\begin{array}{c}\text { Medical illness that developed or worsened during } \\
\text { deployment }\end{array}$ & $\begin{array}{c}4 \\
(13 \%) \\
\end{array}$ \\
\hline Exposure to depleted uranium & 0 \\
\hline Acinetobacter or leishmaniasis & 0 \\
\hline Other infectious disease & $1(3 \%)$ \\
\hline Military sexual trauma & 0 \\
\hline Post-traumatic stress disorder & $\begin{array}{c}6 \\
(20 \%) \\
\end{array}$ \\
\hline Depression & $\begin{array}{c}9 \\
(30 \%) \\
\end{array}$ \\
\hline Alcohol or substance abuse & $\begin{array}{c}4 \\
(13 \%) \\
\end{array}$ \\
\hline Marital problems & $\begin{array}{c}6 \\
(20 \%)\end{array}$ \\
\hline Family problems & $2(7 \%)$ \\
\hline Legal or financial problems & 0 \\
\hline
\end{tabular}

Twenty-nine (78\%) of the responding physicians also reported encountering 1 or more patients in the prior 12 months who had told them that their spouse or partner or other close family member had been deployed to Afghanistan or Iraq. Seventeen (58\%) of these physicians reported treating or referring these family members for depression, alcohol or substance abuse, and/or marital, family, or legal/financial problems. Fifty-one percent $(\mathrm{N}=19)$ of the responding physicians indicated that they were interested in receiving continuing medical education on one or more topics related to post-deployment health. Fifteen expressed interest in learning more about general post-deployment health, 14 expressed interest in PTSD, and 8 indicated they wanted to learn more about TBI.

\section{Discussion}

The results of this study indicate that the majority of community-based primary care physicians who responded to our survey are providing care to patients who have either been deployed to the Afghanistan or Iraq war zones or had a family member deploy. Although these physicians noted a variety of conditions related to physical trauma, mental illnesses and psychosocial disruptions appeared to be more prevalent among their previously deployed patients and were also noted among family members of deployed veterans. In spite of efforts to encourage seamless transition from the DoD health care system to the VA, which include providing 5 years of free care for all veterans of the Afghanistan and Iraq conflict, [6] these results suggest that some veterans eligible for care in the VA are instead seeking care in community-based primary care clinics. Although many veterans may have access to private health insurance or simply prefer non-VA care, community-based physicians who care for them should be aware of the special needs of veterans, especially those who served in combat zones.

Community-based physicians may feel confident in their ability to coordinate or treat the physical sequelae of deployment-related trauma, but appear to face greater uncertainty when attempting to manage the mental health and psychosocial consequences of deployment. This may be especially true regarding PTSD, which was the most frequently selected continuing medical education topic the providers expressed interest in after postdeployment health issues in general. Referral options for deployment-related conditions such as PTSD may be limited because of the relative lack of mental health providers in the community trained to provide evidencebased treatments, especially in rural settings, and because some private insurance plans do not offer parity in mental health coverage [6]. In addition, studies indicate that OEF/OIF active duty personnel and veterans may avoid seeking treatment for conditions such as 
PTSD or depression because of stigma and negative perceptions about mental health care [6,30,31].

It may therefore be helpful for community-based physicians who encounter patients with post-deployment health care needs to be aware of the specialized services and resources available though the VHA and other agencies dedicated to caring for veterans and their families. In spite of initial problems that arose during the early years of the Afghanistan and Iraq conflicts when the VA was overwhelmed by the large number of traumatized veterans seeking care, the VA has dramatically increased resources and services for OEF/OIF veterans and made a concerted effort to provide stateof-art care for conditions such as traumatic brain injury and PTSD. Community-based primary care physicians therefore should consider the system of coordinated care available to all former military, reservists, and National Guard members who served in Afghanistan or Iraq through the VHA, especially for those who have mental health conditions and limited mental health benefits. In addition, several short screening measures that have been validated for use among military personnel recently returned from combat and other provider resources are available to the public at the VA's National Center for PTSD website http://www.ptsd.va. gov/professional/index.asp.

The Department of Veterans Affairs also operates a system of Vet Centers that are organizationally separate from VA medical centers [32]. The Vet Centers provide readjustment counseling and outreach services to combat veterans and their families. In addition, a recent report prepared by the RAND Corporation has catalogued a number of non-federal resources available to OEF/OIF veterans and their families [6]. These include a number of nationwide and regional programs such as the Coming Home Project and Operation Comfort that provide support and free counseling or psychotherapy for returning OEF/OIF veterans and their families, statesponsored programs to assist veterans with their mental health needs, and university counseling services designed specifically for veteran students [6].

Fewer programs and resources are available, however, to government contractors who served in Afghanistan and Iraq. In spite of having similar experiences and conditions as military combat personnel, they are not authorized to receive care from Department of Defense or VA medical facilities. With the exception of contractors who are also veterans or retired military, community-based physicians and mental health providers are likely the only options that government contractors have. Although the Defense Base Act requires that defense contractors provide workers' compensation insurance for civilian employees who work in war zones, recent news reports indicate that about half of the claims for PTSD that have been filed by government contractors have been denied or challenged by insurers $[33,34]$. Virtual support groups for government contractors have started to appear on the world-wide web, but it is imperative we begin to develop additional resources for these civilian veterans.

There are several limitations in the interpretation of findings from this study, including the relatively small sample size. Because the metropolitan area in which the clinics were located is home to several military bases, as well as National Guard and Reserve units, and is also noted for a large population of retired veterans, these results may not generalize to other regions of the country that have less of a military presence. We did not attempt to corroborate providers' self-reports with chart reviews and it is possible that their retrospective recall of post-deployment exposure or deployment-related health concerns may have been subject to memory bias. This study, however, has provided a preliminary glimpse into post-deployment health care needs encountered by physicians in community-based primary care clinics.

\section{Conclusions}

Although the problem of detecting and providing appropriate assistance for post-deployment mental health problems among military personnel and their spouses among military primary care settings has been previously noted, [22,35] this research focused on postdeployment health care needs encountered by primary care physicians in non-military, community-based primary care clinics. The post-deployment health priorities identified by physicians in this study are consistent with those identified in our prior work among patients seeking care in the same non-VA clinical network - namely, the central importance of addressing psychological and psychosocial concerns post-deployment, and the cumulative effect of deployment and post-deployment stressors on the health of family members as well as individual veterans [36]. More research is needed comparing outcomes of those who served in Iraq or Afghanistan and who are cared for in the VA to those who receive care in non-VA community settings. Additional research is also needed on the ability of these different groups of veterans to get the care they need, and the social and emotional impact of their deployment on their families and communities. Primary care physicians remain the first and only point of contact for comprehensive health care for many of those who have served their country. These data suggest that community-based providers should be aware of common post-deployment health conditions and the resources that are available to meet these needs. 


\section{Acknowledgements}

The authors acknowledge the participation and commitment of the members of the South Texas Ambulatory Research Network (STARNet). Grant support

This work was supported by the Department of Veterans Affairs, Veterans Health Administration, Health Services Research and Development Service (HSR\&D) project no. LIP 66-014 and the South Central Area Health Education Center. The funding sources had no role relating to study design; collection, analysis, and interpretation of data; in the writing of the manuscript; or in the decision to submit the manuscript for publication. Dr. Noël is a Research Psychologist at the South Texas Veterans Health Care System. The views expressed in this article are those of the author(s) and do not necessarily represent the views of the Department of Veterans Affairs.

\section{Author details}

${ }^{1}$ VERDICT, Central Texas Veterans Health Care System Scott \& White, 7400 Merton Minter Blvd, San Antonio, Texas 78229 USA. ${ }^{2}$ University of Texas Health Science Center at San Antonio, 7703 Floyd Curl Drive, San Antonio, Texas 78229 USA. ${ }^{3}$ Agency for Healthcare Research \& Quality, 540 Gaither Road, Rockville, MD 20850 USA.

\section{Authors' contributions}

PHN, MLP, MJP, and JEZ conceptualized the study. PHN, JEZ, and MLP obtained funding for the study. JEZ supervised data collection. PHN and JEZ directed data analysis. PHN drafted and finalized the manuscript. All authors contributed to interpreting study results and writing the manuscript. All authors read and approved the final manuscript.

\section{Competing interests}

The authors declare that they have no competing interests.

Received: 3 January 2011 Accepted: 29 July 2011

Published: 29 July 2011

\section{References}

1. Michelle Tan: 2 million troops have deployed since $9 / 11$. MilitaryTimes 2009 [http://www.militarytimes.com/news/2009/12/ military_deployments_121809sw], Accessed March 21, 2010) [Web Page].

2. Department of Defense Press Resources Website: Operation Iraqi Freedom (OIF) \& Operation Enduring Freedom (OEF) U.S. Casualty Status [Web Page]. [http://www.defense.gov/news/casualty.pdf], Accessed 12 December 2006) [Web Page].

3. McNeil JD, Pratt JW: Combat casualty care in an air force theatre hospital: perspectives of recently deployed cardiothoracic surgeons. Semin Thorac Cardiovasc Surg 2008, 20(1):78-84.

4. Kauvar DS, Wolf SE, Wade CE, Cancio LC, Renz EM, Holcomb JB: Burns sustained in combat explosions in Operations Iraqi and Enduring Freedom (OIF/OEF explosion burns). Burns 2006, 32(7):853-7.

5. Sayer NA, Chiros CE, Sigford B, Scott S, Clothier B, Pickett T, et al: Characteristics and rehabilitation outcomes among patients with blast and other injuries sustained during the Global War on Terror. Arch Phys Med Rehabil 2008, 89:163-170.

6. Tanielian T, Jaycox LH: Invisible Wounds of War: Psychological and Cognitive Injuries, Their Consequences, and Services to Assist Recovery. San Diego, California: RAND Corporation; 2008.

7. Milliken CS, Auchterlonie JL, Hoge CW: Longitudinal assessment of mental health problems among active and reserve component soldiers returning from the Iraq War. JAMA 2007, 298(18):2141-2148.

8. Hoge CW, Terhakopian A, Castro CA, Messer SC, Engel CC: Association of posttraumatic stress disorder with somatic symptoms, health care visits, and absenteeism among Iraq war veterans. The American Journal of Psychiatry 2007, 164:150-153.

9. Kang HK, Bullman TA: Risk of suicide among US veterans after returning from the Iraq or Afghanistan war zones. JAMA 2008, 300(6):652-3.

10. Seal $K H$, Bertenthal D, Miner CR, Sen S, Marmar C: Bringing the war back home: Mental health disorders among 103,788 U.S. veterans returning from Iraq and Afghanistan seen at Department of Veterans Affairs facilities. Archives of Internal Medicine 2007, 167:476-482.

11. Sayers SL, Farrow VA, Ross J, Oslin DW: Family problems among recently returned military veterans referred for a mental health evaluation. Journal of Clinical Psychiatry 2009, 70(2):163-170.
12. Polusny MA, Erbes CR, Arbisi PA, Thuras P, Kehle SM, Rath M, Courage $C$, Reddy MK, Duffy C: Impact of prior Operation Enduring Freedom/ Operation Iraqi Freedom combat duty on mental health in a predeployment cohort of National Guard soldiers. Military Medicine 2009, 174(4):353-7.

13. Reger MA, Gahm VA, Swanson RD, Duma SJ: Association between number of deployments to Iraq and mental health screening outcomes in U.S. Army soldiers. Journal of Clinical Psychiatry 2009, 70(9):1266-1272.

14. Cohen SP, Brown C, Kurihara C, Plunkett A, Nguyen C, Strassels SA: Diagnoses and factors associated with medical evacuation and return to duty for service members participating in Operation Iraqi Freedom or Operation Enduring Freedom: a prospective cohort study. 2010, 375:301-309.

15. Sullenberge I, Gentlesk PJ: Cardiovascular disease in a forward military hospital during Operation Iraqi Freedom: a report from deployed cardiologists. Military Medicine 2008, 173(2):193-197.

16. Zouris JM, Wade AL, Magno CP: Injury and illness casualty distributions among U.S. Army and Marine Corps personnel during Operation Iraqi Freedom. Mil Med 2008, 173:247-252.

17. Gironda RJ, Clark ME, Massengale JP, Walker RL: Pain among veterans of Operations Enduring Freedom and Iraqi Freedom. Pain Medicine 2006, 7:339-343.

18. Kerns RD, Dobscha SK: Pain among veterans returning from deployment in Iraq and Afghanistan: update on the Veterans Health Administration Pain Research Program. Pain Med 2009, 10:1161-1164.

19. Kizer KW, Dudley RA: Extreme makeover: Transformation of the Veterans Health Care System. Annual Review of Public Health 2009, 20:313-39.

20. VHA Office of Public Health and Environmental Hazards. Analysis of VA health care utilization among US Global War on Terrorism (GWOT) veterans. , October 2007 Accessed on March 21, 2010 http://gulfwarcouncil. com/DrRokke/va\%20GWOT\%20HealthcareUtil.Presentation3rdQtrfinal102007.ppt\#256,1.

21. Associated Press: Nearly 800 Contractors Killed. USA Today 2007 [http:// www.usatoday.com/news/world/iraq/2007-02-23-contractors_x.htm], February 23. Accessed on January 7, 2010 at.

22. Eaton KM, Hoge CW, Messer SC, Whitt AA, Cabrera OA, McGurk D, Cox A, Castro CA: Prevalence of mental health problems, treatment need, and barriers to care among primary care-seeking spouses of military service members involved in Iraq and Afghanistan deployments. Military Medicine 2008, 173(11):1051.

23. SteelFisher GK, Zaslavsky AM, Blendon RJ: Health-Related Impact of Deployment Extensions on Spouses of Active Duty Army Personnel. Military Medicine 2008, 173(3):221-229.

24. Cozza SJ, Chun RS, Polo JA: Military families and children during Operation Iraqi Freedom. Psychiatric Quarterly 2005, 76(4):371-378.

25. American Psychological Association: The psychological needs of U.S. military service members and their families: a preliminary report. APA Presidential Task Force on Military Deployment Services for Youth 2007.

26. McFarlane AC: Military deployment: the impact on children and family adjustments and the need for care. Current Opinion in Psychiatry 2009, 22:369-373.

27. Chandra A, Lara-Cinisomo S, Jaycox L, Tanielian T, Burns R, Ruder T, Han B: Children on the homefront: the experience of children from military families. Pediatrics 2010, 125.

28. Friedman MJ: Prevention of psychiatric problems among military personnel and their spouses. New England Journal of Medicine 2010, 362(2):168-170.

29. Parchman ML, Zeber J, Pugh JA, Romero RL: Risk of coronary artery disease in type 2 diabetes and the delivery of care consistent with the chronic care model in primary care settings: A STARNet study. Medical Care 2007, 45(12):1129-1134.

30. Hoge CW, Castro CA, Messer SC, McGurk D, Cotting DI, Koffman RL: Combat duty in Iraq and Afghanistan, mental health problems, and barriers to care. N Engl J Med 2004, 351(1):13-22.

31. Pietrzak RH, Johnson DC, Goldstein MB, Malley JC, Southwick SM: Perceived stigma and barriers to mental health care utilization among OEF-OIF veterans. Psychiatric Services 2009, 60(8):1118-22.

32. Vet Center Home Page. United States Department of Veteran Affairs. [http://www.vetcenter.va.gov/], Accessed March 26, 2010.

33. Risen J: Combat stress afflicts civilian contractors returning from Iraq: Mental health issues often slip under the radar. New York Times New 
Service 2007 [http://www.nytimes.com/2007/07/05/us/05contractors.html? pagewanted=all], Accessed March 12, 2010.

34. Miller TC: Contractors in Iraq are hidden casualties of war. ProPublica; 2009 [http://www.propublica.org/article/kbr-contractor-struggles-after-iraqinjuries-1006 ], Accessed March 12, 2010.

35. Coetzee RH, Simpson RG, Greenberg N: Detecting post-deployment mental health problems in primary care. JR Army Med Corp 2010, 156(3):196-199.

36. Finley EP, Zeber JE, Pugh MJ, Cantu G, Copeland LA, Parchman ML, Noel PH: Postdeployment health care for returning OEF/OIF military personnel and their social networks: a qualitative approach. Mil Med 2010, 175(12):953-7.

\section{Pre-publication history}

The pre-publication history for this paper can be accessed here: http://www.biomedcentral.com/1471-2296/12/79/prepub

doi:10.1186/1471-2296-12-79

Cite this article as: Noël et al: A pilot survey of post-deployment health care needs in small community-based primary care clinics. BMC Family Practice 2011 12:79.

\section{Submit your next manuscript to BioMed Central} and take full advantage of:

- Convenient online submission

- Thorough peer review

- No space constraints or color figure charges

- Immediate publication on acceptance

- Inclusion in PubMed, CAS, Scopus and Google Scholar

- Research which is freely available for redistribution

Submit your manuscript at www.biomedcentral.com/submit 